\title{
FURTHER OBSERVATIONS ON THE LEUKOCYTIC RESPONSE IN- DUCED BY THE INTRAMUSCULAR INJECTION OF LIVER EXTRACT ${ }^{1}$
}

\author{
By JOHN H. POWERS, with the assistance of Cynthia Van Doren
}

(From the Department of Surgery and the Surgical Laboratory of the Mary Imogene Bassett Hospital, Cooperstown, New York)

(Received for publication May 28, 1935)

The leukocytogenic effect of the intramuscular administration of liver extract (Lederle) to normal individuals has been presented in a previous paper (1). The response in every instance was due both to an actual and relative increase in the polymorphonuclear neutrophils. The purpose of the present communication is two-fold: first, to submit suggestions regarding the source of this leukocytic response; and secondly, to determine the value of its clinical application in the treatment of surgical patients with infection and no leukocytosis, or definite leukopenia.

\section{Source of the leukocytic response}

Method. The subjects were all normal individuals, either members of the staff, secretaries, and technicians, or convalescent, afebrile, surgical patients on the wards of the Mary Imogene Bassett Hospital.

Two methods of experimental procedure were followed. In the first group, a series of observations covering 3 consecutive days was carried out according to the method of Powers and Murphy (1). The first and third days were utilized as control periods in order to obtain the normal daily range of the leukocytic level and the average differential Schilling count at representative hours before and after the administration of liver extract. At 9 o'clock on the morning of the second day an additional control count was taken and directly thereafter $3 \mathrm{cc}$. of liver extract ${ }^{2}$ were injected intramuscularly in the gluteal region. Complete studies were then made hourly until 7 o'clock in the evening. Thus it was possible not

\footnotetext{
1 Read before the American Society for Clinical Investigation, Atlantic City, May 6, 1935.

2 This extract was prepared by the Lederle Laboratories, Inc., and furnished through the kindness of $\mathrm{Dr}$. Guy W. Clark.
}

only to confirm the previous experimental results (1) but also to determine whether the attendant leukocytosis was due to the liberation of mature neutrophils, juvenile forms, or both.

The second group of observations covered a period of 18 consecutive hours. A control count was taken at 5 o'clock in the morning and $3 \mathrm{cc}$. of liver extract were injected immediately thereafter. Complete determinations were then made at hourly intervals until 11 o'clock in the evening. It was hoped thereby to obtain more information concerning the duration of the leukocytic response and to gather. some data regarding the maturation of the immature cells, should these be found to be increased in the peripheral circulation.

Blood for each count was taken from the finger into a standardized pipette, diluted, shaken for 3 minutes and counted in a standardized Levy counting chamber. Both pipettes and hemocytometers were certified by the U. S. Bureau of Standards and the same instruments were used for all the observations on any one subject. Duplicate cover-slip preparations were made in the usual manner and stained with Wright's stain. Each smear was counted separately, and at random, in order that the result might not be affected by memory of the previous differential identification for the same hour.

One hundred cells in each of the 2 preparations were classified according to the method of Schilling. In general the results varied within a narrow range; the average was utilized in preparing the charts.

Results. There were 4 individuals in the first group. The results are presented in composite, graphic form in Figure 1. The curves representing the total white count, the total number. and percentage of polymorphonuclear neutrophils are identical with those presented in the previous paper and require no discussion, except to point 
out again that the leukocytic response is entirely neutrophilic in character. The point of major importance in the present studies is the relatively greater increase in both total number and percent-

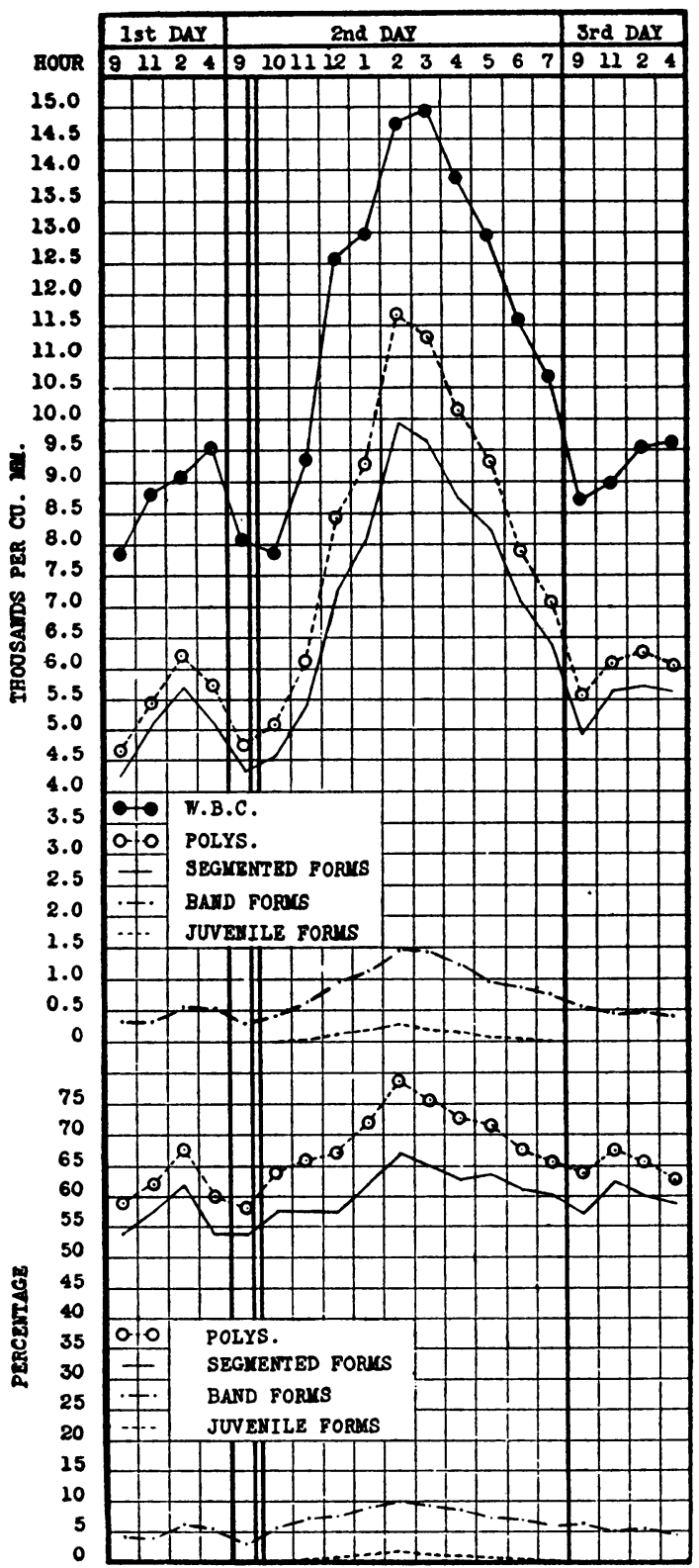

Fig. 1. A Composite Graph of the Total White Cells per cu. mm. and the Total Number and Percentage of Neutrophils, Segmented Forms, Band Cells and Juveniles of 4 Normal Subjects.

The single heavy vertical lines separate the chart into days; the intramuscular injection of $3 \mathrm{cc}$. of liver extract is indicated by the double line. age of young forms compared with the mature cells. Reference to Table I discloses the fact that while the total number of neutrophils per cu. $\mathrm{mm}$. increased 112 per cent, the band forms, or young cells, increased 235 per cent while the segmented forms gained only 96 per cent. The number of

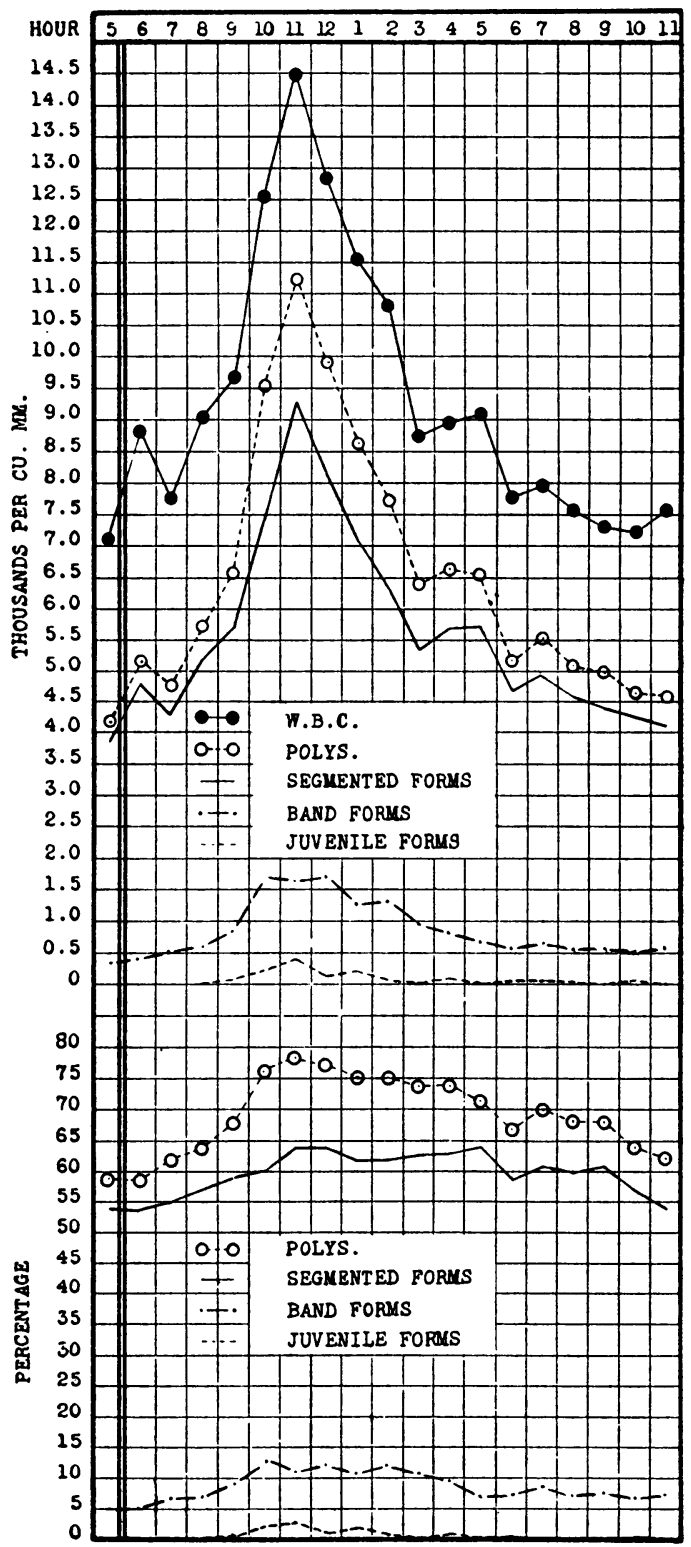

Fig. 2. A Composite Graph of the Total White Cells per cu. mm. and the Total Number and Percentage of Neutrophils, Segmented, Band and Juvenile Forms of 3 Normal Subjects During 18 Consecutive Hours After the Intramuscular Injection OF Liver Extract. 
TABLE I

Tabulation of the actual increase per cu. mm. and the percentage increase of total white cells, polymorphonuclear neutrophils, segmented, band, and juvenile forms at the peak of the leukocytic rise in the first series of experiments

\begin{tabular}{|c|c|c|c|c|c|c|c|c|c|}
\hline & W.B.c. & $\begin{array}{c}\text { Tota } \\
\text { polymor } \\
\text { nuclea }\end{array}$ & & Segmented & forms & Band & prms & Juvenile & rms \\
\hline 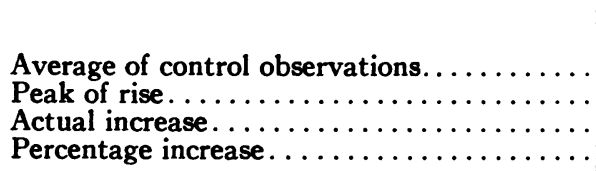 & $\begin{array}{r}\text { per } \\
c u . m m . \\
8,850 \\
14,770 \\
5,920 \\
67\end{array}$ & 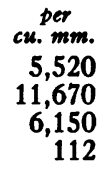 & $\begin{array}{l}\text { per } \\
\text { cent } \\
62 \\
79 \\
17 \\
27\end{array}$ & $\begin{array}{l}\text { per } \\
c u . m m . \\
5060 \\
9900 \\
4840 \\
96\end{array}$ & $\begin{array}{l}\text { per } \\
\text { cent } \\
57 \\
67 \\
10 \\
17\end{array}$ & $\begin{aligned} \begin{array}{c}\text { per } \\
\text { cu. } m m . \\
440 \\
1480 \\
1040 \\
235\end{array}\end{aligned}$ & $\begin{array}{c}\text { per } \\
\text { cent } \\
4.9 \\
10.0 \\
5.1 \\
104.0\end{array}$ & $\begin{array}{c}\text { per } \\
c u . ~ m m . \\
0 \\
270 \\
270\end{array}$ & $\begin{array}{l}\text { per } \\
\text { cent } \\
0 \\
1.8 \\
1.8\end{array}$ \\
\hline
\end{tabular}

juveniles increased from zero to 270 per. cu. mm. Expressed in terms of the Schilling differential formula the per cent of band forms more than doubled while that of the mature cells increased only 17 per cent.

The same facts are even more apparent in the second series of observations. This group was composed of 3 normal subjects to whom liver extract was administered immediately after blood was taken for control studies at 5 o'clock in the morning. A composite curve of the results is presented in Figure 2. As usual, the peak of the rise occurred 6 hours after the injection. The total number of white cells per cu. mm. doubled, and the neutrophils increased 169 per. cent; while the number of mature cells multiplied 143 per cent, the band forms nearly tripled that figure by a maximum gain of 370 per cent. The juveniles increased from zero to 400 per cu. mm. (Table II). Expressed in terms of the Schilling differential again, the percentage of band forms increased 131 per. cent while that of the mature cells gained only 18 per cent. In other words, a distinct shift to the left occurred in each series of experiments.

The longer period of observations in the second group possibly threw some light upon the phe- nomenon of cellular maturation. The number of young cells in the peripheral blood decreased more slowly following the peak of the rise than did either the total neutrophils or the mature forms (Figure 2). From these experiments one might surmise that the transitional period of immaturity, during which the young cell passes from a myelocyte to an adult form with a multilobed nucleus requires a few hours only. The duration of the leukocytic response was essentially the same as in all previous experiments.

Discussion. These findings confirm the previous observations by the author (1) and also by Meyer, Middleton, and Thewlis (2) that the leukocytosis induced by the intramuscular injection of liver extract is entirely neutrophilic in character. Furthermore, they demonstrate that this leukocytic response is due to an increase in both young and mature cells in the circulating blood, with the increase in young forms proportionately greater, both numerically and relatively, than that of the adult cells. These observations suggest that the response is the result of some direct action or effect of liver extract upon the bone marrow. Meyer and his collaborators (2) came to this same conclusion although they were unable to demonstrate a shift to the left in the Schilling counts of

TABLE II

Tabulation of the actual increase per cu. mm. and the percentage increase of total white cells, neutrophils, segmented, band, and juvenile forms at the peak of the rise in the second group of experiments

\begin{tabular}{|c|c|c|c|c|c|c|c|c|c|}
\hline \multirow[b]{2}{*}{ 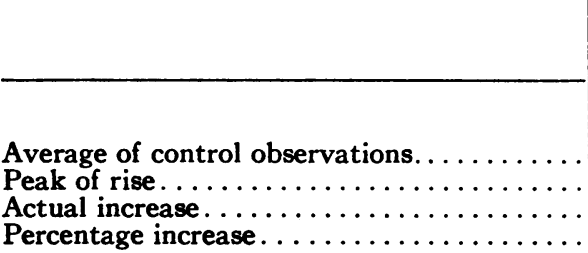 } & \multirow{2}{*}{$\begin{array}{r}\text { W.B.C. } \\
\text { per } \\
\text { cu. mm. } \\
7,080 \\
14,440 \\
7,360 \\
104\end{array}$} & \multicolumn{2}{|c|}{$\begin{array}{c}\text { Total } \\
\text { polymorpho- } \\
\text { nuclears }\end{array}$} & \multicolumn{2}{|c|}{ Segmented forms } & \multicolumn{2}{|c|}{ Band forms } & \multicolumn{2}{|c|}{ Juvenile forms } \\
\hline & & $\begin{array}{r}\text { per } \\
\text { cu. mm. } \\
4,180 \\
11,260 \\
7,080 \\
169\end{array}$ & $\begin{array}{c}\text { per } \\
\text { cent } \\
59 \\
78 \\
19 \\
32\end{array}$ & $\begin{array}{c}\text { per } \\
\text { cu. mm. } \\
3820 \\
9280 \\
5460 \\
143\end{array}$ & $\begin{array}{c}\text { per } \\
\text { cent } \\
54 \\
64 \\
10 \\
18\end{array}$ & $\begin{array}{c}\text { per } \\
\text { cu. mm. } \\
340 \\
1600 \\
1260 \\
370\end{array}$ & $\begin{array}{r}\text { per } \\
\text { cent } \\
4.8 \\
11.1 \\
6.3 \\
131.0\end{array}$ & $\begin{array}{c}\text { per } \\
\text { cu. mm. } \\
0 \\
400 \\
400\end{array}$ & $\begin{array}{l}\text { per } \\
\text { cent } \\
0 \\
2.8 \\
2.8\end{array}$ \\
\hline
\end{tabular}


4 normal individuals at the peak of the rise. Such a shift did occur, however, in 1 patient with Banti's disease following the intramuscular injection of liver extract (Lederle). In this patient, and in 1 other with splenomegaly, well marked leukocytic responses followed the parenteral use of extract, both before and after. removal of the spleen. In fact, the leukocytosis was more marked in each instance after splenectomy than before. This rise was preceded by a drop in the leukocytic level immediately following the injection, an observation which is in direct opposition to the studies of Miller and Rhoads (3).

These observers describe an increase in all the formed elements of the blood, including the leukocytes, 20 minutes after the intravenous administration of liver extract to a patient with anemia and splenomegaly. This response was coincidental with contraction of the spleen which could be demonstrated both clinically and roentgenologically, and they conclude that the spleen must be considered not only as a reservoir of red blood cells but also as a storehouse for proportionately greater numbers of white cells and blood platelets. Similar splenic contractions were induced by the intramuscular administration of adrenaline, histamine, and eserine. Injection of the 2 former drugs was followed promptly by an increase in the number of leukocytes in the peripheral blood; no reaction was noted after the use of eserine. These observations are interesting in view of the marked leukocytosis which followed the injection of extract after splenectomy in the patients of Meyer and his collaborators. One must conclude from their experiments at least that the spleen did not act as a reservoir for the white cells, and that the leukocytosis which followed the intramuscular injection of liver extract was due either to direct or indirect stimulation of the bone marrow.

\section{Value of liver extract in the treatment of cer- tain types of infection}

In the large majority of cases the presence of pathogenic organisms in the human body is, in itself, a powerful leukocytogenic stimulant. There are certain patients, however, either so overwhelmed by an acute process, or so debilitated by chronic infection that no leukocytic response takes place. It was in these groups of individuals that the practical value of liver extract was tested in a very small series of cases. Only 3 patients thus far have seemed suitable for such a clinical trial.

\section{PROTOCOLS}

\section{Case 1}

The patient was a married woman, 26 years of age, who was referred to the hospital because of chills and a high fever. A spontaneous abortion occurred 1 month previously. Persistent vaginal bleeding terminated in a severe hemorrhage 2 weeks later. The vagina was packed by her family doctor; severe abdominal cramps ensued, and the packing was dislodged by a second hemorrhage. Except for headache and a slight fever she was then free from symptoms until the day before admission when she had a sudden chill with elevation in temperature to $104^{\circ} \mathrm{F}$.

The patient was exceedingly toxic and presented the appearance of an individual with an overwhelming infection. Except for flushed cheeks, the skin and mucous membranes were pale. There was no abdominal tenderness or spasm. Motion of the cervix was painful; the uterus was enlarged, boggy, and tender.

The temperature was $104^{\circ} \mathrm{F}$., and the pulse rate was 134; the following day the temperature rose to $105.8^{\circ}$ and the pulse to 140 . Blood cultures failed to substantiate the clinical impression of bacteremia. The patient ran a spiking fever with wide daily swings ranging between $98.6^{\circ}$ and $105.2^{\circ}$ for 2 weeks. Thereafter the temperature gradually subsided to normal and she was discharged 26 days after admission.

Diagnoses: Early abortion, incomplete; endometritis, septic; anemia secondary to acute and chronic loss of blood.

Procedure. When these observations were made, the usual interval between the injection of extract and the maximal leukocytic response in normal individuals had not been determined. Hence 10 o'clock in the morning and 4 in the afternoon were chosen as arbitrary hours for acquiring samples of blood. Injections of $3 \mathrm{cc}$. of liver extract, indicated by the single vertical lines in Figure 3, were made at 8 o'clock in the evening of the preceding day as represented on the chart. Direct transfusions of $500 \mathrm{cc}$. of whole blood, shown by the double vertical lines, were given on the second and eighth days in the hospital.

Result. In spite of the first transfusion the white count dropped precipitously during the subsequent 3 days from 18,050 to 8,900 and the neutrophils from 13,740 to 6,320 . After the first and second injections of liver extract an even more abrupt rise occurred; the leukocytes jumped from 10,000 to 20,900 and the neutrophils from 7,500 to 17,970 per cu. $\mathrm{mm}$. The response after the third administration is difficult to evaluate because of the subsequent transfusion which was warranted by the extreme seriousness of the patient's condition. Two later injec- 
tions were each followed by a definite but less spectacular elevation of the leukocytic count.

The detailed observations are presented graphically in Figure 3 and are correlated with the temperature, erythrocytic count, and percentage of hemoglobin in Figure 4.

Case 2

The patient was a 33 year old housewife who induced an abortion by the introduction of a catheter 8 days prior to admission to the hospital. The following morning she passed a 2 months' fetus, placenta and intact membranes. After 4 days of moderate vaginal bleeding, the discharge became foul; fever, headache, and general malaise ensued.

The patient was extremely pale except for a malar flush. The skin and mucous membranes were dry and the tongue was coated. The abdominal wall was flabby but soft throughout and free from tenderness except in the suprapubic region; with deep inspiration the spleen

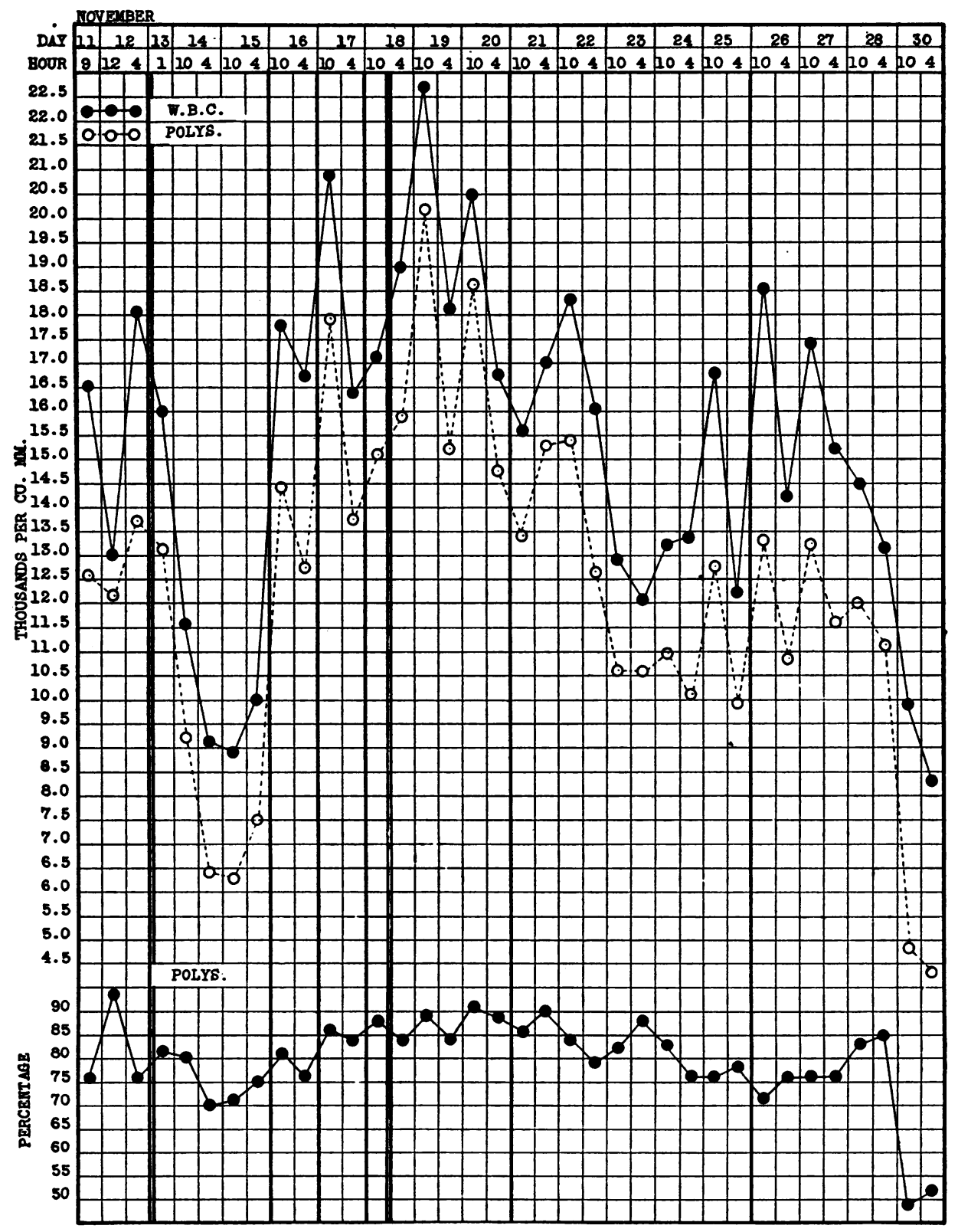

Fig. 3. Chart of the Individual Observations in Case 1.

The injections of extract are indicated by the single heavy vertical lines, transfusions of whole blood by the double lines. 


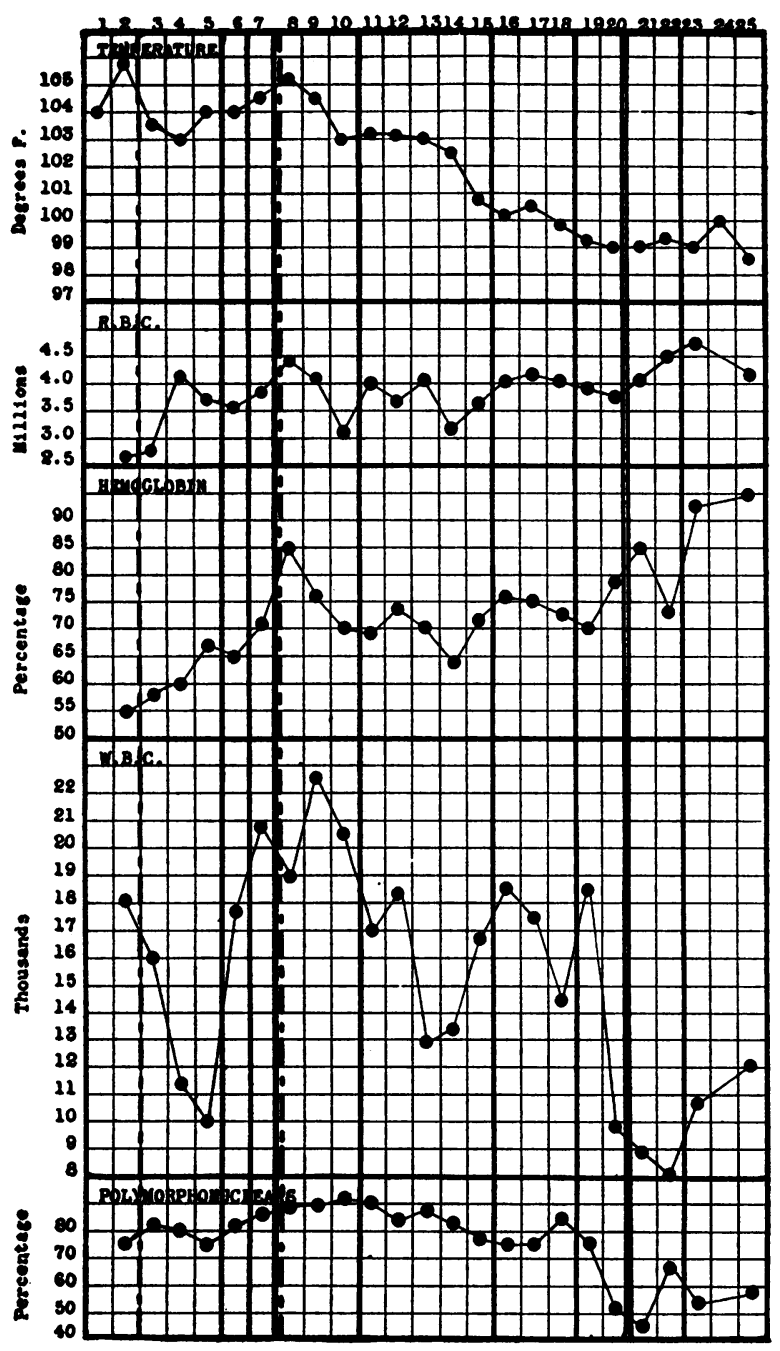

Fig. 4. Correlation of the Highest Daily Temperature, Erythrocytic Count, Hemoglobin, Leukocytic Count and Percentage of Neutrophils in CASE 1.

The broken vertical lines indicate transfusions of whole blood, the single solid vertical lines represent intramuscular injections of liver extract, and the double solid vertical lines indicate the beginning of daily oral administration of ferric ammonium citrate.

was palpable $2 \mathrm{~cm}$. below the costal margin. The cervix was soft and patulous, the uterus was enlarged and tender to bimanual palpation; induration and tenderness were present in the posterior cul-de-sac.

The temperature on admission was $103.4^{\circ} \mathrm{F}$., the pulse rate was 110 , the erythrocytic count was $2,230,000$, the hemoglobin 48 per cent by the method of Sahli; the leukocytes were only 3,380 per cu. $\mathrm{mm}$. with 75 per cent polymorphonuclear neutrophils. The subsequent white counts are presented graphically in Figure 5. Culture of the vaginal discharge yielded Streptococcus anhemolyticus and Escherichia coli.

With conservative treatment the temperature and pulse rate subsided to normal in 3 days. The vaginal discharge gradually ceased and the patient was allowed to go home 1 week later. The erythrocytic count at that time was $3,100,000$ and the hemoglobin was 55 per cent.

Diagnoses: Early abortion, complete; endometritis, septic, due to Streptococcus anhemolyticus and Escherichia coli; anemia secondary to chronic loss of blood.

Procedure. The experiments with normal individuals had been conducted prior to the treatment of this patient. Hence a method as nearly comparable as possible was carried out. Three cc. of liver extract were given intravenously at 9 o'clock in the morning of the second, third, fourth, sixth, ninth, and tenth days. Blood for counts and smears was taken each afternoon at approximately two-hourly intervals.

Result. The result is charted graphically in Figure 5. The patient had a pronounced leukopenia on admission, with only 3,380 leukocytes and 2,060 neutrophils, per cu. $\mathrm{mm}$. An immediate response occurred after each injection, with the peak of the rise at about the same interval of time as was noted with normal individuals. A gradual but definite upward trend in the average leukocytic level from day to day also took place, until a maximum of 12,120 white cells and 9,210 neutrophils was reached. The patient's convalescence was uneventful.

\section{Case 3}

The patient, a married woman, 24 years of age, was admitted to the hospital with puerperal sepsis, 8 days after delivery.

Examination disclosed a pale, prostrated, acutely ill individual with dry, parched lips and a coated tongue. The neck was stiff and painful when flexed. The heart was hyperactive, the impulse forceful, and the rate rapid. The abdomen was enormously distended without spasm and with no tenderness except in the suprapubic region. After the abdominal distension had partially subsided, the uterine fundus could be felt mid-way between the symphysis and umbilicus.

The temperature was $104^{\circ} \mathrm{F}$. and the pulse rate, 136. The white count was 12,750 with 80 per cent neutrophils, the red count, 2,990,000, and the hemoglobin 60 per cent. The leukocytic counts in detail and their relations to injections of liver extract, transfusions, and the administration of antistreptococcus serum (New York State Department of Health) are presented in Figure 6.

Vaginal smear yielded Streptococcus hemolyticus and the same organism was obtained from the blood on the seventh day and on numerous occasions thereafter.

During the first week in the hospital clinical improvement and a downward trend in the temperature were noticeable. She was transfused on the sixth day. On the seventh, the temperature was again over $104^{\circ} \mathrm{F}$., and the course thereafter was exceedingly septic. Thrombophlebitis of the left iliac vein developed and death occurred at the end of 5 weeks. 
Diagnoses: Puerperal septicemia and bacteremia due to Streptococcus hemolyticus; acute thrombophlebitis of the vessels of the left lower extremity; anemia secondary to infection.

Procedure. The first 36 hours were utilized as a control period; blood for the usual studies was taken at with a peak of 20,000 nine hours after the last injection (Figure 6). An abrupt drop occurred the following day in spite of a transfusion. The trend thereafter was steadily downward to a constant average level of about 10,000 per cu. mm. which was maintained during the remainder of the patient's illness.

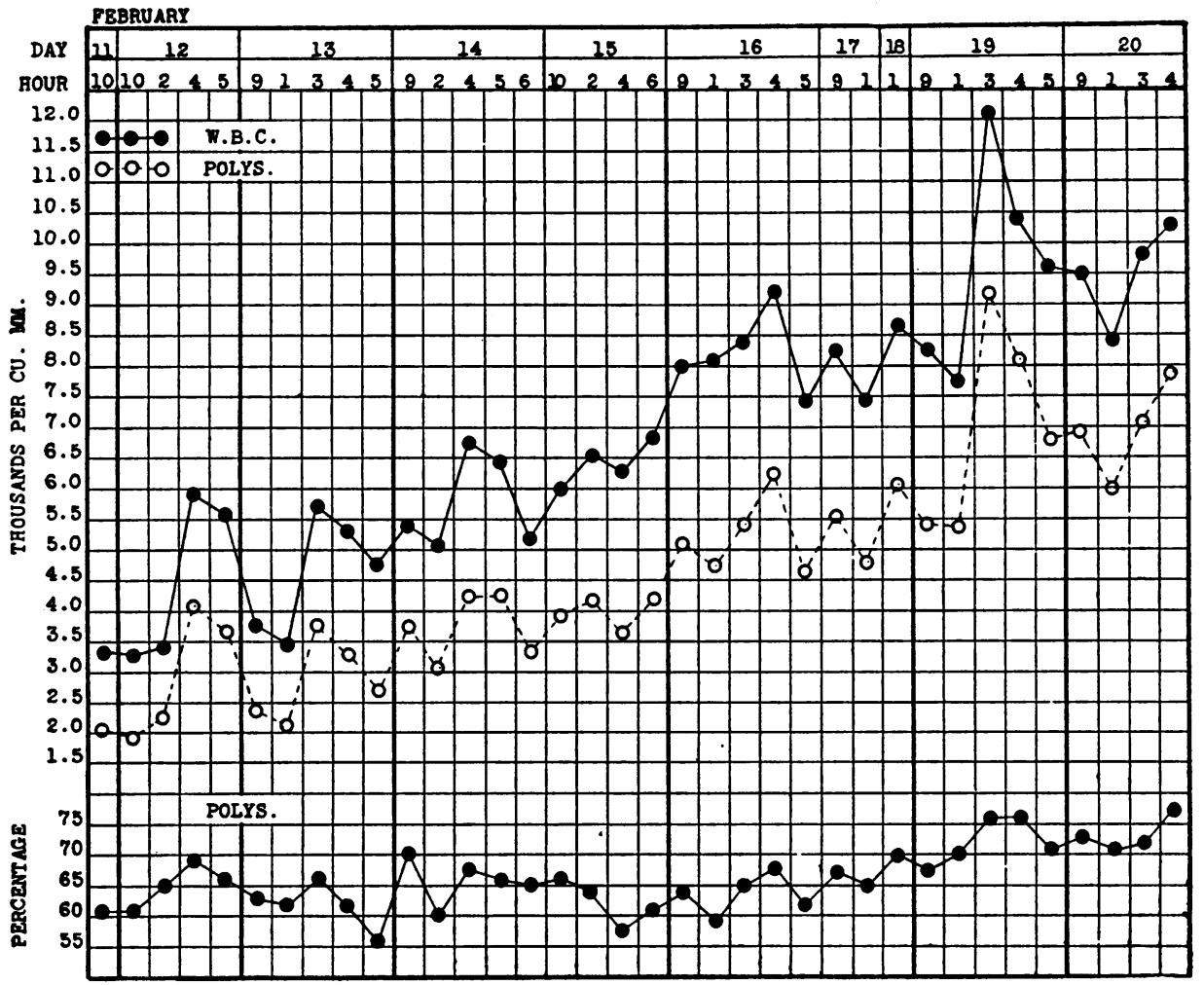

Fig. 5. Chart of the Individual Observations in Case 2.

The injections of liver extract are indicated by the single vertical lines.

intervals of 2 hours during the day in order to obtain the range of the leukocytic level before treatment was instituted. The patient was then given 3 cc. of liver extract intramuscularly at 8 o'clock in the morning of the following 3 successive days and the observations were repeated at the same two-hourly intervals. The author was not personally in charge of this patient and the injections were discontinued thereafter. Blood for counts was taken at less frequent intervals for several days longer, however, and the leukocytic curve presents a sharp contrast to that which was observed during the period of treatment with liver extract.

Result. During the first 6 days in the hospital the patient's clinical condition improved. The highest daily elevation in temperature dropped from $104^{\circ} \mathrm{F}$. to $102^{\circ} \mathrm{F}$. and the pulse rate showed a perceptible downward trend. Three injections of liver extract were given during this period and the total white count rose from an average level of 10,390 per cu. mm. on the day before treatment was instituted to an average of 17,230 on the third day
Comment. No conclusions may be drawn from such a small group of patients. In each of the cases presented, however, a well marked elevation of the leukocytic count followed the intramuscular use of liver extract. Two patients, who were exceedingly ill upon admission to the hospital, recovered but it is very probable that recovery would have occurred without the use of extract as a leukocytogenic stimulant. In one case, the eventual outcome was fatal but clinical improvement was apparent during the period of treatment.

Several favorable reports (4), (5) have appeared in the recent literature on the value of liver extract in the treatment of agranulocytic angina. Murphy (6) has recorded well marked leukocytic responses with recovery in several cases, and feels that the drug has a distinct place in the treatment 


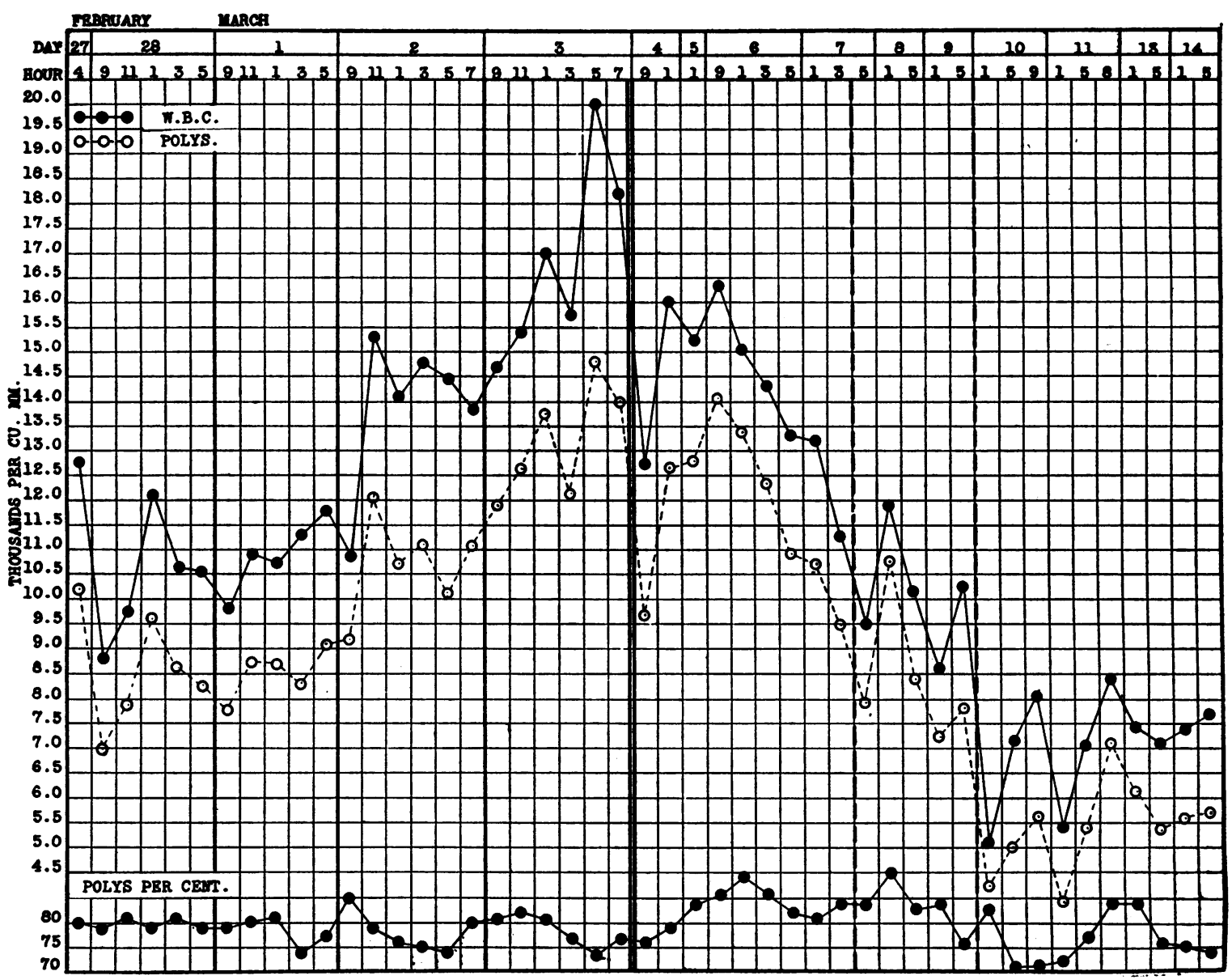

Fig. 6. Chart of the Individual Observations in Case 3.

Injections of liver extract are indicated by the single vertical lines, a transfusion of blood by the double lines, and the administration of antistreptococcus serum by the broken lines.

of this disease. If such be true, it seems reasonable to expect that some benefit may be derived from its use in patients with infection accompanied by a less severe degree of leukopenia than that which occurs in the average case of agranulocytosis.

\section{SUM MARY}

Observations on the degree and character of the leukocytic response induced by the intramuscular administration of liver extract to 7 normal subjects and to 3 surgical patients with infection have been described and presented in graphic form.

The normal individuals were divided into 2 groups. To the first of these $3 \mathrm{cc}$. of liver extract were given at 9 o'clock in the morning; ob- servations made the day preceding and the day following the experiment were utilized as controls. The leukocytic response was entirely neutrophilic in character, and reached its peak in 6 hours, and was composed of a relatively greater increase ( 235 per cent) in the young or band forms than in the mature cells (96 per cent). The number of juveniles increased from zero to 270 per cu. $\mathrm{mm}$.

There were 3 normal subjects in the second group who received the same amount of extract at 5 o'clock in the morning. The total white cells doubled, the neutrophils increased 169 per cent and the band forms, 370 per cent. The juveniles rose from zero to 400 per cu. $\mathrm{mm}$. The peak of the rise again occurred 6 hours after the injection. The number of young cells disappeared relatively more slowly from the peripheral blood than did 
the mature forms. The results suggest that the leukocytosis induced by the intramuscular administration of liver extract to normal individuals is due either to direct or indirect stimulation of the bone marrow.

Three surgical patients, 1 with puerperal sepsis and bacteremia, and 2 with septic endometritis were given liver extract intramuscularly. In each case the leukocytic count was low before the injections were started and a well marked leukocytosis occurred thereafter. The response was entirely neutrophilic in character.

\section{BIBLIOGRAPHY}

1. Powers, J. H., and Murphy, W. P., Leukocytosis fol- lowing the intramuscular injection of liver extract. J. Clin. Invest., 1933, 12, 713.

2. Meyer, O. O., Middleton, W. S., and Thewlis, E. M., Leukocytosis after parenteral injection of liver extract. Am. J. M. Sc., 1934, 188, 49.

3. Miller, D. K., and Rhoads, C. P., The effect of splenic contraction on the formed elements of the blood in a case of anemia and splenomegaly. J. Clin. Invest., 1933, 12, 1009.

4. v. Bonsdorff, B., Lebertherapie bei Granulocytopenie. Klin. Wchnschr., 1934, 13, 1079.

5. Martin, W. B., Treatment of malignant neutropenia by injection of liver extract. Am. J. Clin. Path., 1934, 4, 438.

6. Murphy, W. P., Some effects of the intramuscular injection of a concentrated solution of liver extract. Address Before the Utica Academy of Medicine, Utica, New York, February 24, 1935. 